\title{
Topology redesign for performance by large admissible perturbations
}

Received: 23 April 2004 / Revised manuscript received: 13 July 2005 / Published online: 9 January 2006 (C) Springer-Verlag 2006

\begin{abstract}
A methodology is developed for optimal structural topology design subject to several performance constraints. Eight-node solid elements are used to model the initial structure, which is a uniform solid block satisfying the boundary conditions and subjected to external loading. The Young modulus of each solid element or group of elements is used as redesign variable. A minimum change function is used as an optimality criterion. Performance constraints include static displacements, natural frequencies, forced response amplitudes, and static stresses. These constraints are treated by the large admissible perturbation methodology which makes it possible to achieve the performance objectives incrementally without trial and error or repetitive finite element analyses for changes in the order of $100-300 \%$. Thus, the optimal topology is reached in about four to five iterations, where each iteration includes one finite element analysis and setting of an upper limit for the value of the modulus of elasticity to produce a manufacturable structure. Several numerical applications are presented using three different benchmark structures to demonstrate the methodology and the impact of performance constraints on the generated topology.
\end{abstract}

Keywords Topology - Performance - Optimization · Structural redesign $\cdot$ Large admissible perturbations

\section{Background}

The goal of structure optimization is to improve the performance of any given objective set in a structural environment

\section{Miao $(\square)$}

Offshore Engineering Department,

American Bureau of Shipping,

16855 Northchase Drive,

Houston, TX 77060, USA

e-mail:1miao@eagle.org

M. M. Bernitsas

Department of Naval Architecture and Marine Engineering,

University of Michigan, 2600 Draper Rd.,

Ann Arbor, MI 48109-2145, USA

e-mail: michaelb@engin.umich.edu of loads, constraints, and restraints. Such restraints can be some performance specifications such as natural frequencies, static displacements, static stresses, and forced-response amplitudes. At the simplest level, this can be achieved by sizing optimization. Shape optimization takes the process to a higher level by modifying the boundary of a structure. Topology design is the ultimate form of structure optimization dealing with material distribution and material properties. Structural topology optimization is a fairly recent development. It first evolved from distributed parameter approaches to shape optimization. In optimizing the spatial thickness distribution of plate structures, Cheng and Olhoff (1981) recognized that regions of zero thickness were openings in plate structures. This technique was used in structural topology optimization by Kohn and Strang (1986) and was demonstrated by Bendsoe and Kikuchi (1988) utilizing a homogenization approach. The latter method formulated a homogenized elasticity tensor at the microstructure level to model a unit cell with a rectangular void. The dimensions and orientation angles of the voids are used as the design variables for the optimization problem to minimize the compliance of a structure subject to a volume constraint. Yang and Chuang (1994) used a material distribution method in which the material density is penalized to force the design variables to be either zero or one. In both methods, the goal is structural compliance minimization or structural stiffness maximization. Evolutionary structural optimization (ESO) was introduced by Xie and Steven (1993) by gradually removing low-stressed elements to achieve the optimal design using minimum weight or compliance as objective function. Recently, several papers have been published pointing to the similarities of structures appearing in nature and topologies evolved by topology optimization (Walters 2002; Mattheck and Tesari 2002; Pasini and Burgess 2002).

The performance aspect of a structure is considered by using performance-based functionals. Generally, a performance-based topology design problem is to maximize one of the performances of the structure subject to pure cost constraints such as a volume constraint on structural material. Ma et al. (1995) maximized a set of eigenvalues of the structure subject to a volume constraint. However, the performance- 
based features of a structure can be any of the following or combinations thereof: static displacements, natural frequencies, forced dynamic amplitudes, and static stresses. The LargE Admissible Perturbation (LEAP) theory, introduced into topology redesign by Suryatama and Bernitsas (2000), makes it possible to impose several performance constraints simultaneously.

The large admissible perturbation theory was first developed to formulate and solve the redesign problem, which is the process of finding an objective structure which satisfies a set of design goals starting from an initial structure. It has been developed at the University of Michigan since 1983, and it can presently solve large-scale redesign problems allowing for large structural changes without trial and error or repetitive finite element analyses. Hoff and Bernitsas (1985) introduced static and modal dynamic redesign. These two objectives were integrated by Kim and Bernitsas (1990) for redesign, satisfying both objectives simultaneously. Bernitsas and Tawekal (1991) solved the problem of model calibration by LEAP in a cognate space. Stiffened plate and shell elements were added by Bernitsas and Rim (1994). Bernitsas and Suryatama (1999) improved the static deflection redesign algorithm by introducing static mode compensation. Bernitsas and Blouin (1999) solved the problem of redesign for forced-response amplitude, and static stress redesign was implemented by Kristanto and Bernitsas (2003). At this stage, large admissible perturbation methods implemented in code REdesign of STRUCTures (RESTRUCT) have been used to solve various redesign problems using spring, truss, bar, beam, plate, shell, solid elements for combinations of redesign constraints on static deflections, modal dynamics, static stresses, and forcedresponse amplitudes.

In this paper, a heuristic evolutionary algorithm is developed to find a new topology which satisfies multiple performance constraints simultaneously in four to five iterations. Each iteration evolves one finite element run and redesign based on large admissible perturbation methodology. To make the structure easy to manufacture, the use of two materials of different values of Young's Modulus is introduced. The advantages of the developed approach are illustrated by several numerical applications, which are all benchmarking problems in the topology design literature.

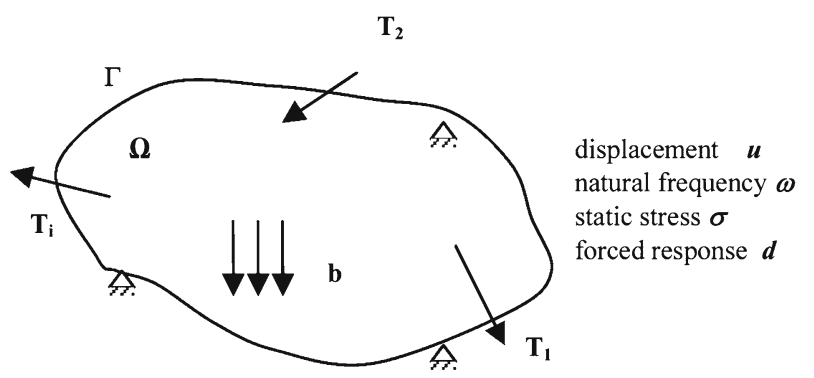

Fig. 1 Design domain and performance specifications

\section{Topology redesign formulation}

Topology redesign starts from a solid continuum with homogeneous material. The goal is to evolve the topology of a structure in the process of minimizing an optimization criterion while satisfying the performance specifications (constraints). Static displacements $u$, natural frequencies $\omega$, static stresses $\sigma$, and forced-response amplitudes d are typical performance constraints as seen in Fig. 1.

In 3-D finite element modeling, the baseline solid block is composed of solid elements. The consistent mass matrix of an isotropic element is

$\left[m_{e}\right]=\rho_{e} \int_{V_{e}}\left[N_{e}\right]^{T}\left[N_{e}\right] \mathrm{d} V$,

where $\rho_{e}$ is the element density, $V_{e}$ is the element volume, and $\left[N_{e}\right]$ represents the interpolation function matrix for each element. For the entire structure, which consists of $n_{e}$ elements, the mass matrix is

$[m]=\sum_{e=1}^{n_{e}}\left[m_{e}\right]$

which shows that structural mass change can be achieved by changing the element density only. Similarly, the stiffness equation $\left[k_{e}\right]$ of an isotropic solid element is

$\left[k_{e}\right]=E_{e} \int_{V_{e}}\left[B_{e}\right]^{T}\left[D_{e}\right]\left[B_{e}\right] \mathrm{d} V$,

where $E_{e}$ is the elastic modulus, $\left[D_{e}\right]$ is the constitutive law matrix, and $\left[B_{e}\right]$ is the strain-nodal displacement matrix. Since $E_{e}$ is constant for each element, the stiffness of an element can be modified by changing $E_{e}$.

Assuming that $\rho_{e}$ and $E_{e}$ are constant for each element, their fractional changes, $a_{e}$, of an element or a group of elements can be used as design variables. Thus,

$\rho_{e}^{\prime}=\rho_{e}\left(1+\alpha_{\rho_{e}}\right)$,

$E_{e}^{\prime}=E_{e}\left(1+\alpha_{E_{e}}\right)$,

where $\alpha_{\rho_{e}}$ and $\alpha_{E_{e}}$ are fractional changes of $\rho_{e}$ and $E_{e}$, respectively.

Accordingly, the topology optimization problem can be formulated as follows:

Minimize $\sum_{e=1}^{p} \alpha_{e}^{2}$

subject to $n_{\omega}$ natural frequency constraints

$\omega_{i}^{\prime 2}=b_{\omega_{i}} \quad i=1,2, \ldots n_{\omega}$

$n_{u}$ static displacement constraints

$u_{i}^{\prime}=b_{u_{i}} \quad i=1,2, \ldots n_{u}$ 
$n_{d}$ forced-response amplitude constraints

$d_{i}^{\prime}=b_{d_{i}} \quad i=1,2, \ldots n_{d}$

$n_{d}$ forced-response amplitude constraints

$\sigma_{i}^{\prime}=b_{\sigma_{i}} \quad i=1,2, \ldots n_{\sigma}$

$n_{a}$ admissibility constraints from among the complete set

$\left\{\phi^{\prime}\right\}_{j}^{T}\left[k^{\prime}\right]\left\{\phi^{\prime}\right\}_{i}=0$

$\left\{\phi^{\prime}\right\}_{j}^{T}\left[m^{\prime}\right]\left\{\phi^{\prime}\right\}_{i}=0$

$i=1, \ldots, n_{\omega}, \quad j=i+1, \ldots, n_{r}$

and $2 p$ lower and upper bounds on the redesign variables.

$-1<\alpha_{e}^{-} \leq \alpha_{e} \leq \alpha_{e}^{+}, \quad e=1,2, \ldots, p$.

where $\alpha_{e}$ is element redesign variable, $p$ is the number of redesign variables, $\alpha_{e}^{-}$is the lower bound set by the designer for each redesign variable, and $\alpha_{e}^{+}$is the upper bound set by the designer for each redesign variable.

In the above formulation, the optimization criterion is the norm of the change between the initial solid block (baseline) and the resulting evolved structure (objective). Any other optimization criterion such as minimum weight can be used. Further, primed quantities refer to the objective structure, and the unprimed quantities refer to the baseline structure; the admissibility conditions are defined in Appendix B. Further, $b_{\omega_{i}}, b_{u_{i}}, b_{d_{i}}$, and $b_{\sigma_{i}}$ are the designer performance specifications.

A typical solution approach in structural topology optimization requires $40-100$ iterations with one finite element run per iteration to satisfy a volume constraint while minimizing the compliance. Alternatively, a functional of natural frequencies is minimized subject to a volume constraint.

The problem formulated in this paper satisfies several performance objectives. To avoid excessive computation and numerous finite element runs, the general perturbation equations presented in the next section are used to manipulate the performance constraints in (7)-(10).

\section{Performance constraints}

To solve the optimization problem, all the performance constraints must be expressed as functions of redesign variables. Using the LEAP methodology, the general perturbation equations can be derived (see Appendix A, B), expressing the performance of the unknown state $\mathrm{S} 2$ in terms of properties of S1 and redesign variables. Unprimed and primed symbols refer to states S1 and S2, respectively. Mathematical symbols in this paper are defined in the Nomenclature.

In the initial state $\mathrm{S} 1$, the static and modal dynamic equilibrium equations for finite element analysis are

$[k]\{u\}=\{f\}$, $\left([k]-\omega^{2}[m]\right)\{\phi\}=\{0\}$.

For state $\mathrm{S} 2$, the counterpart equilibrium equations are

$\left[k^{\prime}\right]\left\{u^{\prime}\right\}=\left\{f^{\prime}\right\}$,

$\left(\left[k^{\prime}\right]-\omega^{\prime 2}\left[m^{\prime}\right]\right)\left\{\phi^{\prime}\right\}=\{0\}$.

Quantities of states S1 and S2 are related as follows:

stiffness matrix : $\left[k^{\prime}\right]=[k]+[\Delta k]$,

mass matrix $\quad:\left[m^{\prime}\right]=[m]+[\Delta m]$,

mode shape : $\left\{\phi^{\prime}\right\}=\{\phi\}+\{\Delta \phi\}$,

displacement : $\left\{u^{\prime}\right\}=\{u\}+\{\Delta u\}$,

where $\Delta$ represents change between the initial state $\mathrm{S} 1$ and the unknown state $\mathrm{S} 2$. Such changes obviously depend on the redesign variables. Substituting (18) and (19) into (16) and (17) yields

$$
\begin{gathered}
\{\Delta u\}=-\{u\}+([k]+[\Delta k])^{-1}\left\{f^{\prime}\right\}, \\
\left\{\phi^{\prime}\right\}^{T}\left([\Delta k]-\omega^{\prime 2}[\Delta m]\right)\left\{\phi^{\prime}\right\}= \\
-\left\{\phi^{\prime}\right\}^{T}\left([k]-\omega^{\prime 2}\left[m^{\prime}\right]\right)\left\{\phi^{\prime}\right\},
\end{gathered}
$$

where $[\Delta k]$ and $[\Delta m]$ are functions of redesign variables. This should be calculated in the redesign process in terms of the properties of the initial state S1, and the performance specifications for state $\mathrm{S} 2$, such as a few components of $\left\{u^{\prime}\right\}$, $\left\{\omega^{\prime 2}\right\},\left\{\phi^{\prime}\right\},\left\{d^{\prime}\right\},\left\{\sigma^{\prime}\right\}$.

The finite element model is divided into groups of elements, called element sets, such that all the elements within a group have the same redesign variables. We define $\alpha_{e}$ as the fractional change of a structural property, $e$. For instance, if $A$ and $A^{\prime}$ are the cross-sectional areas in a given element set in S1 and S2, respectively, then $\alpha_{A}$ is such that

$A^{\prime}=A\left(1+\alpha_{A}\right)$.

Consequently, changes in stiffness and mass matrices with linear dependency can be expressed by

$$
\begin{aligned}
& {[\Delta k]=\sum_{e=1}^{p}\left[\Delta k_{e}\right]=\sum_{e=1}^{p}\left[k_{e}\right] \alpha_{e},} \\
& {[\Delta m]=\sum_{e=1}^{p}\left[\Delta m_{e}\right]=\sum_{e=1}^{p}\left[m_{e}\right] \alpha_{e} .}
\end{aligned}
$$

(25) is valid for rod and beam elements. In the case of plate elements, however, the stiffness matrix for bending is a cubic function in $\alpha_{e}$ (cubic). For the numerical applications in this paper, eight-node solid elements, designated in MSC/NASTRAN as CHEXA elements, are utilized for the finite element models. The density and the elastic modulus of each element may be used as redesign variables. 
In terms of the density variables, the consistent mass matrix of an isotropic element $\left[m_{e}\right]$ is given by (1). Similarly, the stiffness matrix $\left[k_{e}\right]$ of an isotropic solid element is expressed in terms of the Young's modulus variables as given in (3).

Next, the general perturbation equations for static displacement and modal dynamics are presented. They are used in the numerical applications in Section 5. The general perturbations for static stresses and forced response amplitudes are derived by Bernitsas and Blouin (1999) and Kristanto and Bernitsas (2003), respectively.

\subsection{Static displacement constraints}

By substituting (25) into (22), the static general perturbation equation can be expressed in terms of $\alpha_{e}$ 's as

$\{\Delta u\}=-\{u\}+\left([k]+\sum_{e=1}^{p}\left[k_{e}\right] \alpha_{e}\right)^{-1}\left\{f^{\prime}\right\}$.

(27) is transformed into (28) as shown in Appendix A.

$u_{i}^{\prime}=u_{i}-\sum_{m=1}^{n_{r}} \phi_{i, m}^{\prime} \frac{\sum_{e=1}^{p}\left\{\phi^{\prime}\right\}_{m}^{T}\left[k_{e}\right]\{u\} \alpha_{e}}{\left\{\phi^{\prime}\right\}_{m}^{T}\left[k_{e}\right]\left\{\phi^{\prime}\right\}_{m}+\sum_{e=1}^{p}\left\{\phi^{\prime}\right\}_{m}^{T}\left[k_{e}\right]\left\{\phi^{\prime}\right\}_{m} \alpha_{e}}$

$i=1,2, \ldots, n_{u}$,

where $u_{i}$ is the response of the initial structure in the $i$-th degree of freedom and $u_{i}^{\prime}$ is the desired response of the new structure in the $i$-th degree of freedom.

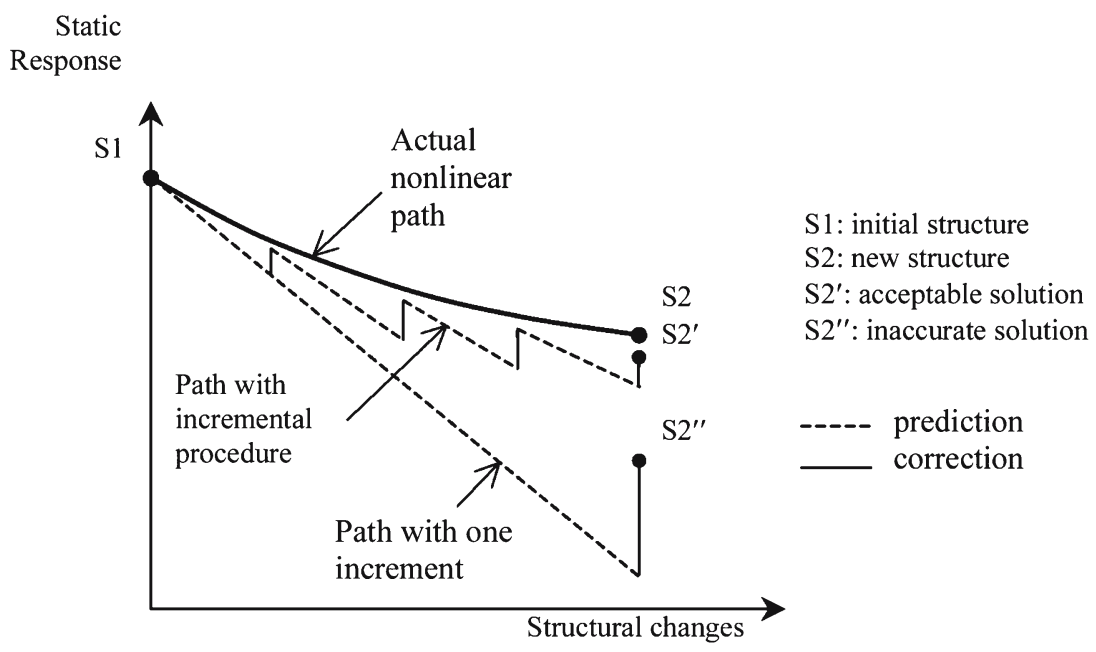

Fig. 2 Schematic representation of solution process

\subsection{Modal dynamic constraints}

Similarly, by substituting (18)-(20) into (23) (see Appendix B), the general perturbation equation for modal dynamics becomes

$$
\begin{array}{r}
\sum_{e=1}^{p}\left(\left\{\phi^{\prime}\right\}_{i}^{T}\left[k_{e}\right]\left\{\phi^{\prime}\right\}_{i}-\omega_{i}^{\prime 2}\left\{\phi^{\prime}\right\}_{i}^{T}\left[m_{e}\right]\left\{\phi^{\prime}\right\}_{i}\right) \alpha_{e} \\
=\omega_{i}^{\prime 2}\left\{\phi^{\prime}\right\}_{i}^{T}[m]\left\{\phi^{\prime}\right\}_{i}-\left\{\phi^{\prime}\right\}_{i}^{T}\left[k_{e}\right]\left\{\phi^{\prime}\right\}_{i}
\end{array}
$$

$i=1,2, \ldots, n_{\omega}$.

The linear appearance of the left-hand side is appropriate for the solid elements used in this paper. For plate elements, the relation is cubic.

\section{Topology evolution algorithm}

The solution algorithm has two nested algorithms. The outside loop deals with the topology evolution, which aims to redistribute material and redefine material properties. The inner loop is based on LEAP and forces the performance constraints. Those two algorithms are explained next.

\subsection{LEAP algorithm for redesign}

(28) and (29), the general perturbation equations, are implicit nonlinear equations with respect to $\alpha_{e}$ 's. These equations cannot be solved directly. An incremental method, consisting of a predictor and a corrector phase in each increment, has been developed to modify these equations so that the optimization algorithm can solve the redesign problem. In this section, the static redesign is used as an example to illustrate the incremental predictor and corrector scheme.

The desired change in static response is divided into $N$ small incremental changes. At each increment, a pre- 
diction-correction scheme is employed. At this point, all variables are rewritten with the exponent-index $l$, indicating the $l$-th increment. This concept is schematically represented in Fig. 2.

Following the global optimization problem defined by (6)-(13), the incremental redesign problem at increment $l$ is formulated as follows:

Minimize $\sum_{e=1}^{p}\left[\left(1+\alpha_{e}^{l}\right) \prod_{q=1}^{l-1}\left(1+\alpha_{e}^{q}\right)-1\right]^{2}$

subject to

$u_{i}^{\prime l}=b_{u_{i}}^{l}, \quad i=1,2, \ldots, n_{u}$,

$\omega_{i}^{2^{l}}=b_{\omega_{i}}^{l}, \quad i=1,2, \ldots, n_{\omega}$,

$d_{i}^{\prime l}=b_{d_{i}}^{l}, \quad i=1,2, \ldots, n_{d}$, $\sigma_{i}^{\prime l}=b_{\sigma_{i}}^{l}, \quad i=1,2, \ldots, n_{\sigma}$,

$\left\{\phi^{\prime}\right\}_{j}^{T^{l}}\left[k^{\prime l}\right]\left\{\phi^{\prime}\right\}_{i}^{l}=0$

$\left\{\phi^{\prime}\right\}_{j}^{T^{l}}\left[m^{\prime l}\right]\left\{\phi^{\prime}\right\}_{i}^{l}=0$,

$i=1, \ldots, n_{\omega}, \quad j=i+1, \ldots, n_{r}$,

and the lower and upper bounds on the redesign variables as

$$
0<\frac{1+\alpha_{e}^{-}}{\prod_{q=1}^{l-1}\left(1+\alpha_{e}^{q}\right)} \leq 1+\alpha_{e}^{l} \leq \frac{l+\alpha_{e}^{+}}{\prod_{q=1}^{l-1}\left(1+\alpha_{e}^{q}\right)},
$$

where $\prod_{q=1}^{l-1}\left(1+\alpha_{e}^{q}\right)$ is known from all previous increments and is, by definition, one for $l=1$. The optimization criterion

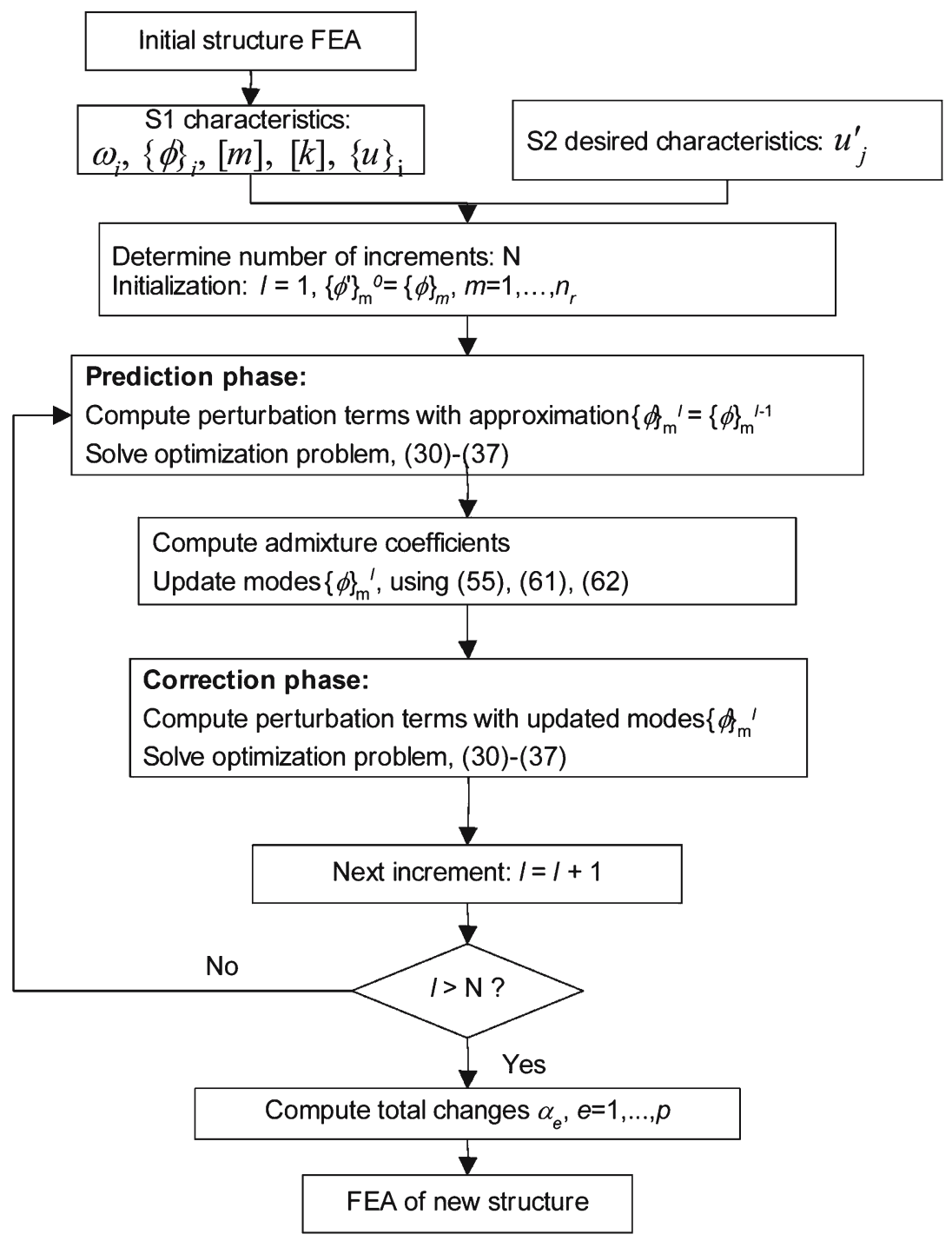

Fig. 3 Algorithmic representation of incremental method 


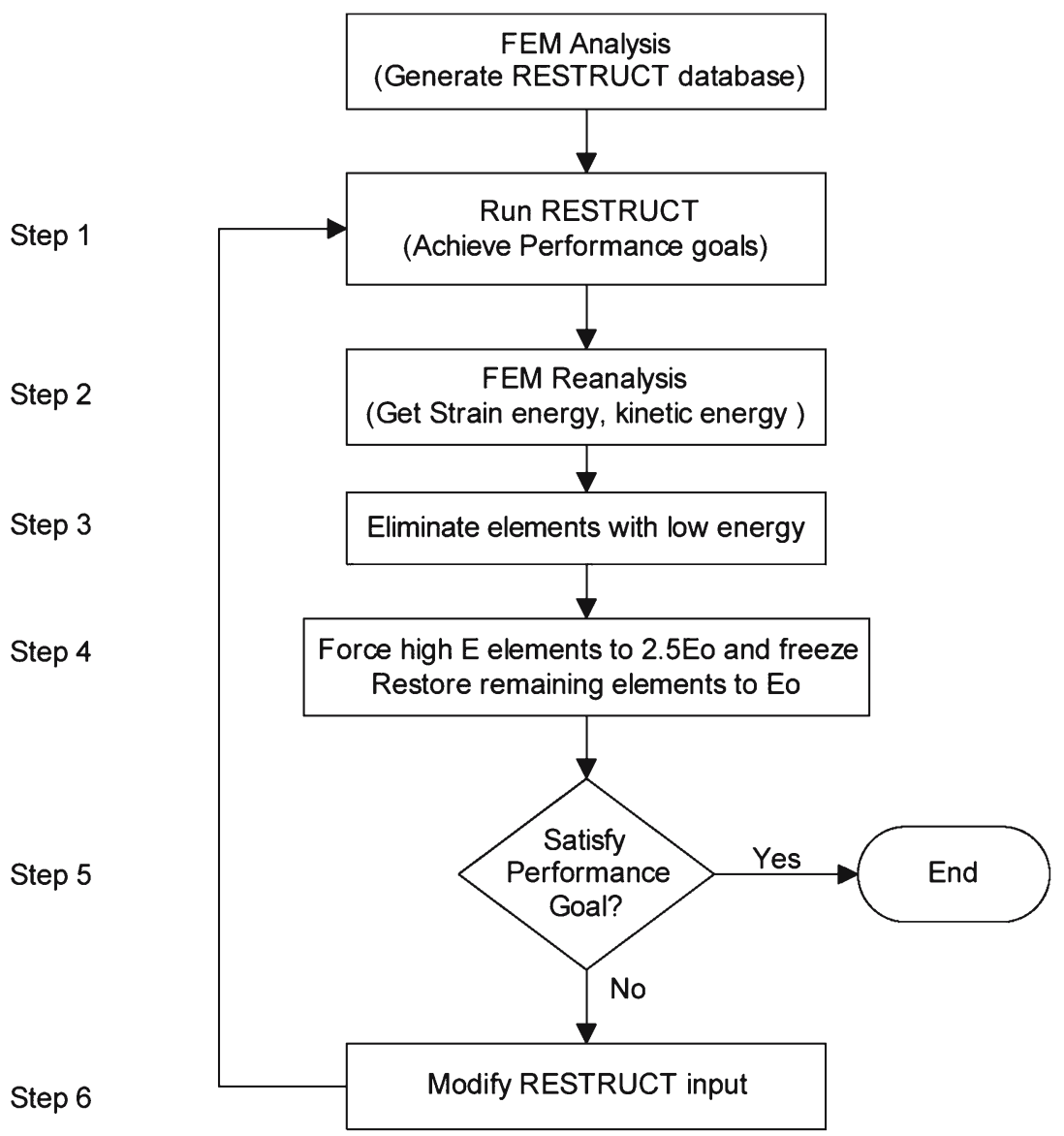

Fig. 4 Topology evolution algorithm

is selected so that at the end of the incremental procedure and at the completion of the solution process, criterion (6) is satisfied since $\left(1+\alpha_{e}\right)=\prod_{q=1}^{l-1}\left(1+\alpha_{e}^{q}\right)$. The performance constraints satisfy the general perturbation equations such as (28) and (29).

At each increment, the optimization problem (30)-(37) must be solved for the unknown incremental fractional changes $\alpha_{e}^{l}, e=1, \ldots, p$. For the prediction phase of the first increment, the eigenvectors $\left\{\phi^{\prime}\right\}_{m}^{l}, m=1, \ldots, n_{\mathrm{r}}$ in (28) are approximated by the known eigenvectors of the initial structure $\{\phi\}_{m}$. For the prediction phase of subsequent increments, the eigenvectors $\left\{\phi^{\prime}\right\}_{m}^{l}$ are approximated by the ones computed in the previous increment $\left\{\phi^{\prime}\right\}_{m}^{l-1}$. The optimization problem is solved for the incremental fractional changes, $\alpha_{e}^{l}, e=1, \ldots$, $p$, which provide a prediction to the solution. From this predicted solution, the eigenvectors $\left\{\phi^{\prime}\right\}_{m}^{l}$ can be updated using (55), (61), and (62) (see Appendix C). Then, the optimization problem is formulated with the new eigenvectors and solved for the fractional changes $\alpha_{e}^{l}, e=1, \ldots, p$, which provide the corrected solution. A schematic representation of the algorithm is shown in Fig. 3. The LEAP methodology and

Table 1 Performance specifications for three applications

\begin{tabular}{|c|c|c|c|c|c|}
\hline & \multicolumn{2}{|c|}{ Performance specifications } & $\begin{array}{l}\text { Application I: } \\
\text { cantilever beam }\end{array}$ & $\begin{array}{l}\text { Application II: } \\
\text { bridge }\end{array}$ & $\begin{array}{r}\text { Application III: } \\
\text { clamped plate }\end{array}$ \\
\hline State $\mathrm{S} 1$ & $\begin{array}{l}u(\mathrm{~mm}) \\
\omega^{2}\end{array}$ & & $\begin{array}{l}0.0109 \\
2.678089 E+10\end{array}$ & $\begin{array}{l}0.6151255 \\
6.184314 E+09\end{array}$ & $\begin{array}{l}0.612357 \\
9.873829 E+08\end{array}$ \\
\hline State S2 (goal) & $\begin{array}{l}\text { Static } \\
\text { Dynamic } \\
\text { Static and } \\
\text { dynamic }\end{array}$ & $\begin{array}{l}u^{\prime} / u \\
\omega^{2 \prime} / \omega^{2} \\
u^{\prime} / u \\
\omega^{2 \prime} / \omega^{2}\end{array}$ & $\begin{array}{l}0.5 \\
1.44 \\
0.68 \\
1.44\end{array}$ & $\begin{array}{l}0.5 \\
1.44 \\
0.68 \\
1.44\end{array}$ & $\begin{array}{l}0.5 \\
1.44 \\
0.68 \\
1.44\end{array}$ \\
\hline
\end{tabular}

The eigenvalue $\omega^{2}$ represents the second mode for application I and the first mode for applications II and III 


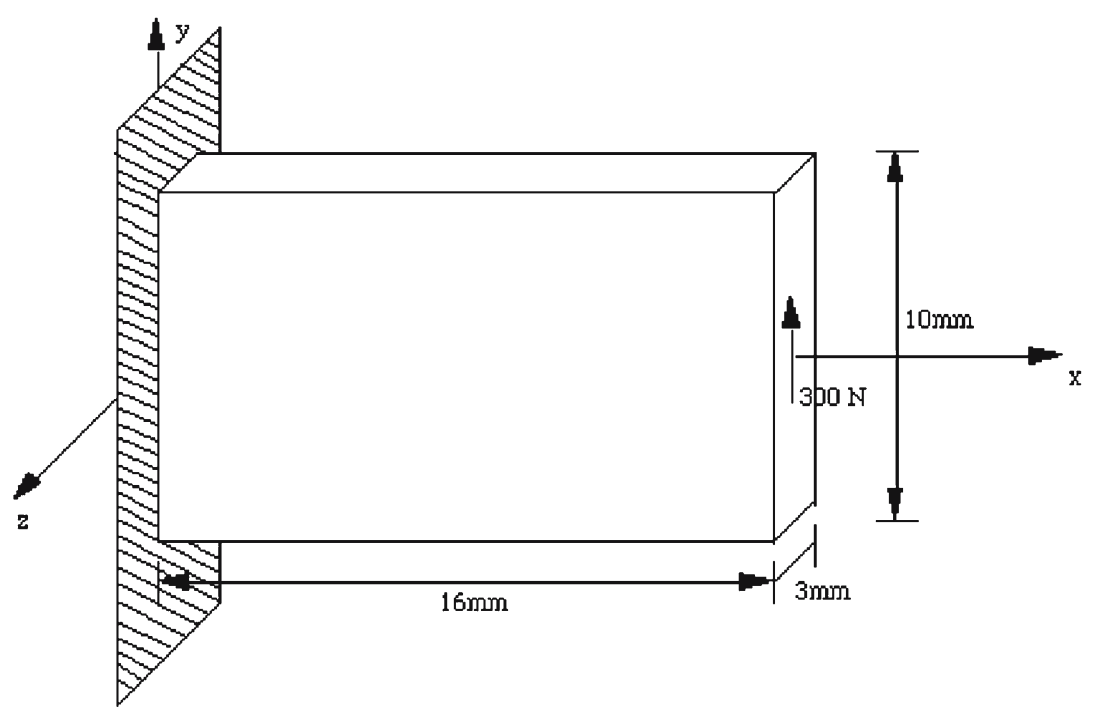

Fig. 5 Initial structure S1: cantilever beam

the algorithm derived above have been implemented in code RESTRUCT. It is written in FORTRAN with about 30,000 commands and postprocesses MSC-NASTRAN data.

\subsection{Evolution algorithm}

The outer algorithm which evolves the new topology in material properties is outlined in Fig. 4 and described below:

Step 1: Perform a finite element analysis by MSCNASTRAN; generate the RESTRUCT database for redesign.

Step 2: Redesign the structure by RESTRUCT to achieve the specified goals.

Step 3: Perform a finite element analysis by MSCNASTRAN; generate the RESTRUCT database and strain energy density distribution and kinetic distribution (with dynamic constraints).

Step 4: Modify RESTRUCT input data and MSC-NASTRAN data files by eliminating redesign variables of elements with energy density below a defined cut-off point (e.g., 1-2\%) of the maximum element energy density.

Where energy density refers to

- Static strain energy density for static topology redesign

- Dynamic strain and kinetic energy density for dynamic topology redesign

- Static strain, dynamic strain, and kinetic energy density for static and dynamic topology redesign

Step 5 Modify RESTRUCT input data and MSCNASTRAN data files by freezing the elements that have elastic modulus larger than an upper bound, say $2.5 E_{0}$. The elastic modulus for these elements is set equal to the upper bound. Restore the elastic modulus of the remaining elements to their initial value $E_{0}$.

Step 6 Does the new topology satisfy the specified structural performance goals? If yes, stop; otherwise, go to Step 1.

Steps 1-6 are repeated until the structure achieves the desired response specified by the designer. As shown in the

\begin{tabular}{|c|c|c|c|c|c|}
\hline Run & 1 & 2 & 3 & 4 & 5 \\
\hline SSE & & & & & \\
\hline E/Eo & & & & & \\
\hline SET & & & & & \\
\hline
\end{tabular}

Fig. 6 Evolution of static topology redesign for cantilever beam 
Table 2 Results of the cantilever plate for static topology redesign

\begin{tabular}{lllll}
\hline $\begin{array}{c}\text { Iteration } \\
\text { number }\end{array}$ & $\begin{array}{c}\text { Static } \\
\left(u^{\prime} / u\right)\end{array}$ & $\begin{array}{c}\text { Redesign } \\
(\text { error \%) }\end{array}$ & $\begin{array}{c}\text { Number of } \\
\text { redesign } \\
\text { variables }\end{array}$ & $\begin{array}{c}\text { SSE } \\
(\text { eliminate } \\
\%)\end{array}$ \\
\hline 1 & 0.503 & 0.32 & 320 & 1.00 \\
2 & 0.887 & 0.55 & 253 & 1.00 \\
3 & 0.867 & 0.61 & 196 & 1.50 \\
4 & 0.629 & 0.87 & 133 & 2.00 \\
5 & 0.695 & 0.69 & 64 & 3.00 \\
\hline
\end{tabular}

numerical applications in Section 5, four to five iterations suffice.

\section{Numerical implementation}

In this section, three benchmark applications are used to demonstrate the topology evolution process and the LEAP algorithm. In each of these applications, the static, modal dynamic, and the combined static and modal dynamic problems are solved, and the performance specifications for each case are listed in Table 1 .

In each redesign application, large topology changes are achieved with only five iterations. At each iteration, an element may either be removed due to its low strain energy, in other words, its low contribution to supporting the load, or preserved into the next iteration. As mentioned in Section 4 (Topology evolution algorithm), the cut-off point is $1-2 \%$ of the maximum strain energy. The cut-off point is chosen in such a way that the new structure remains continuous. The preserved elements are divided into two categories. The first category includes all the elements which at the end of the iteration have Young's modulus $E$ greater or equal to $2.5 E_{0}$. Those elements are reassigned a value of $E$ equal to $2.5 E_{0}$. The second category includes all elements with $E<2.5 E_{0}$. Those are reassigned the original value of $E=E_{0}$.

The results of this process can be seen in the new element set distribution (see SET row in Figs. 6, 7, 8, 9, 10, 11, 12, $13,14,15,16)$, where red represents the higher $E$ elements that are frozen and are not redesigned in the next iteration, light blue represents the elements with $E=E_{0}$, and dark blue is the void following element elimination. The results of each application also show normalized energy distribution at each iteration, where SSE is static strain energy, DSE is dynamic strain energy, KE is kinetic energy, and CE is combined energy. The evolution of normalized elastic modulus distribution, $E / E_{0}$, is also presented in the results.

\subsection{Topology redesign of a cantilever beam}

The structure shown in Fig. 4 is redesigned for topology and performance. It is a cantilever solid structure with an inplane load of $300 \mathrm{~N}$ at the center of the free end. Young's modulus $E_{0}=2.07 \times 10^{5} \mathrm{MPa}$, Poisson's ratio $v=0.3$, and density

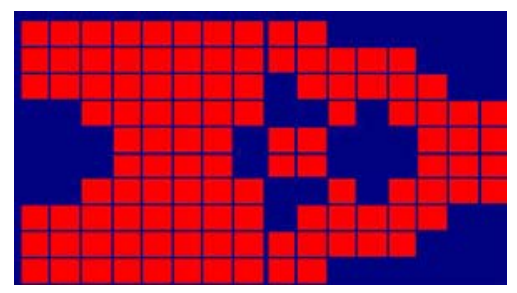

Fig. 7 Evolved topology of static redesign for cantilever beam (160element model)

$\rho=7.833 \times 10^{-9} \mathrm{~N} \mathrm{~s}^{2} / \mathrm{mm}^{4}$. It is modeled by a $32 \times 20$ finite element model (Fig. 5)

Static redesign As shown in Table 1, the static redesign objective is reduction of static displacement at the loading point by a factor of 2 . The results of topology and static performance redesign are shown in Fig. 6 and Table 2. For each iteration, the SSE, the new Young's modulus $\left(E / E_{0}\right)$, and the new element set (SET) are presented. In five iterations, the topology evolution process leads to the cantilever shown in SET (5), which shows two interesting features: (1) a pattern of a repeatable set of three voids and (2) curved elements of variable thickness reminiscent of Gothic arches rather than trusses.

The cantilever plate is also modeled by a $16 \times 10$ mesh to perform static topology redesign. The optimal structure obtained after four iterations is shown in Fig. 7, where all elements with $E_{0}$ elements are vanished, and the structure cannot be redesigned anymore. This is also true for a 640 model as seen in Fig. 6. At step 5, most of the elements left are red with an elastic modulus of $2.5 E_{0}$. Within the resolution error, the similarity between the redesigned topologies using two different meshes shows the robustness of the redesign process.

The result is also validated by comparing the redesigned topology to the results of material density method (Yang and Chuang 1994), as shown in Fig. 8, which was also modeled by $32 \times 20$ elements. A $25 \%$ material usage constraint was imposed. The number of iterations using linear programming is 30 . Although the two structures have different volume reduction, both structures have similarities. Some features, like the stiffened arch and cross bracing, appear in both designs.

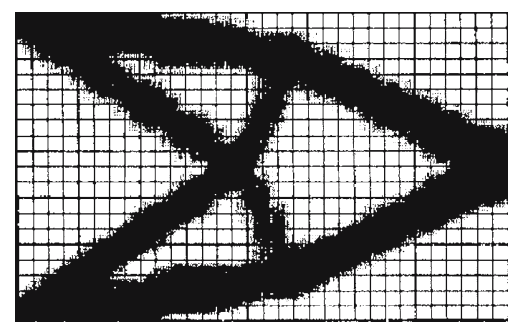

Fig. 8 Evolved topology by material density method (Yang and Chuang 1994) 


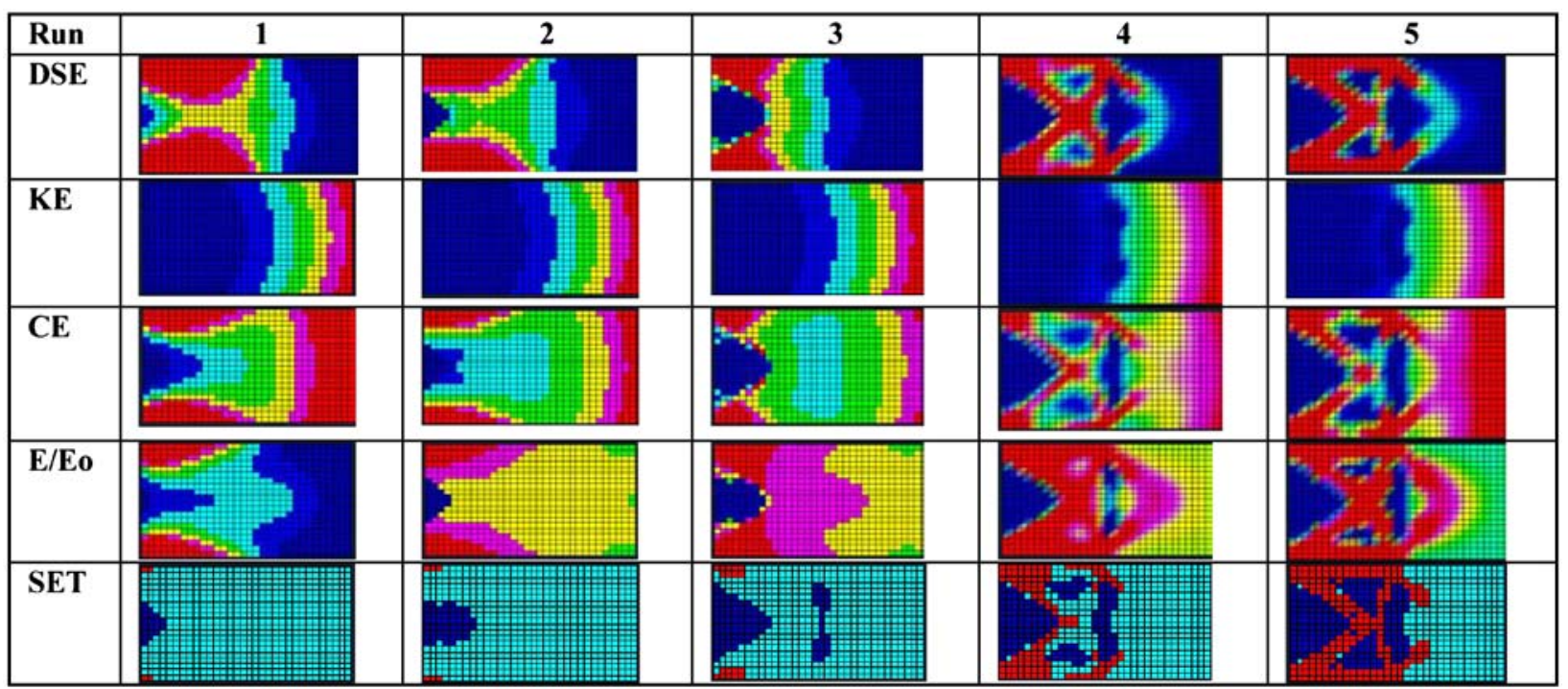

Fig. 9 Evolution of modal dynamic topology redesign for cantilever beam

Modal dynamic redesign As shown in Table 1, the modal dynamic objective is to increase the second eigenvalue (inplane bending) by a factor of 1.44 . The results of topology and modal dynamic performance redesign are shown in Fig. 9 and Table 3. For each iteration, the DSE, KE, CE, the new Young's modulus $\left(E / E_{0}\right)$, and SET are presented. In five iterations, the topology evolution leads to the cantilever shown in SET (5). The main features of the redesigned structure are the following: (1) The part of the structure closer to the clamped end is stiffened and exhibit a pattern of void similar to that of the statically loaded cantilever; (2) the part of the structure away from the clamped end, which does not contribute much to the stiffness of the structure, remains unchanged, providing the mass needed to achieve new natural frequency. These results are intuitively correct.

Simultaneous static and modal dynamic redesign In this application, the cantilever beam in Fig. 5 is redesigned simultaneously for the static and dynamic objectives shown in Table 1. The results are shown in Fig. 10 and Table 4. For each iteration, the SSE, DSE, KE, CE, the new Young's modulus $\left(E / E_{0}\right)$, and SET are presented. Again, in five iterations, the topology evolution process generates SET (5), which is more

Table 3 Results of the cantilever plate for dynamic topology redesign

\begin{tabular}{lllll}
\hline $\begin{array}{c}\text { Iteration } \\
\text { number }\end{array}$ & $\begin{array}{c}\text { Dynamic } \\
\left(\omega^{2 /} / \omega^{2}\right)\end{array}$ & $\begin{array}{c}\text { Redesign } \\
(\text { error \%) }\end{array}$ & $\begin{array}{c}\text { Number of } \\
\text { redesign } \\
\text { variables }\end{array}$ & $\begin{array}{c}\text { CE } \\
\text { (eliminate \%) }\end{array}$ \\
\hline 1 & 1.440 & 1.46 & 320 & 5.00 \\
2 & 1.394 & 0.77 & 308 & 7.00 \\
3 & 1.526 & 1.16 & 291 & 7.00 \\
4 & 2.032 & 4.76 & 259 & 7.00 \\
5 & 1.605 & 1.54 & 185 & 7.00 \\
\hline
\end{tabular}

difficult to verify intuitively. Nevertheless, some of the features observed in the results of the static and modal dynamic redesigns can be observed here. Specifically, areas of voids or higher $E$ elements common to the redesigns in Figs. 6 and 9 appear in Fig. 10 as well. Such is the case at the clamped end and at the point of loading. Further, elements near the free end of the structure are maintained since mass is needed in the modal dynamic topology redesign. The pattern, voids, and stiffening in the middle of the cantilever, however, would be difficult to anticipate intuitively by observing the results of the static and dynamic topology redesigns.

\subsection{Topology redesign of a bridge}

The structure shown in Fig. 11 is modeled using $432(36 \times 12)$ solid elements with Young's modulus $E_{0}=2.07 \times 10^{5} \mathrm{MPa}$, Poisson's ratio $\nu=0.3$, and density $\omega=7.833 \times 10^{-9} \mathrm{~N}$ $\mathrm{s}^{2} / \mathrm{mm}^{4}$. Three concentrated forces are applied with $F=$ $5,000 \mathrm{~N}$ at the bottom of the bridge.

Static redesign As shown in Table 1, the static redesign objective is reduction of static displacement by a factor of 2 at the point of application of load 2F. Fig. 12 presents the results of SSE, $E / E_{0}$, and SET at each iteration, and Table 5 lists the elimination parameters and redesign results for each iteration. In five iterations, the topology evolution process leads to the bridge shown in SET (5), which exhibits the following features: (1) voids, (2) stiffened elements, and (3) curved and straight elements. These features can be justified intuitively.

Modal dynamic redesign As shown in Table 1, the modal dynamic objective is to increase the first eigenvalue (inplane bending) by a factor of 1.44 . The results of topology and modal dynamic performance redesign are shown in Fig. 13 


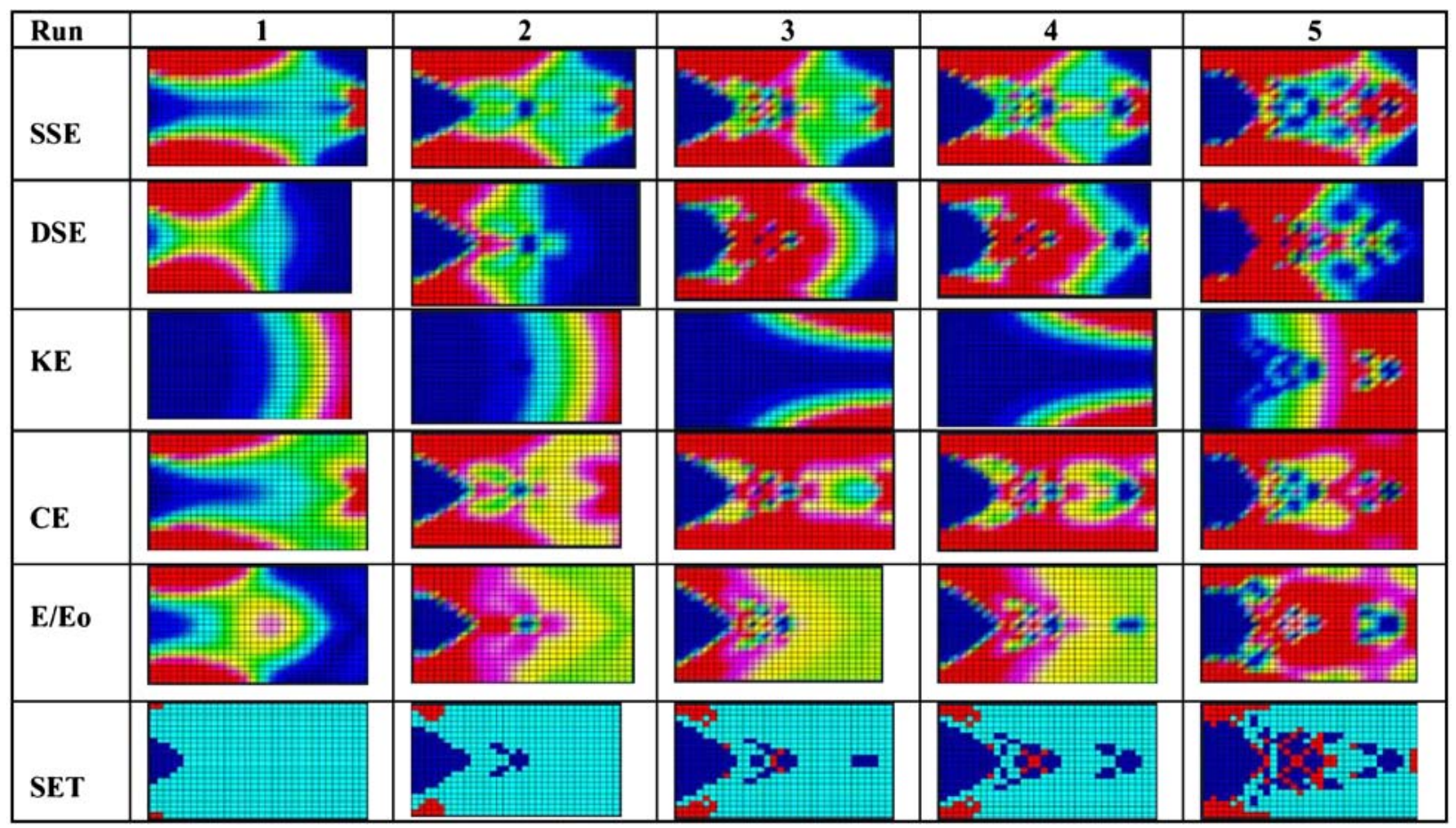

Fig. 10 Evolution of simultaneous static and modal dynamic topology redesign for cantilever beam

and Table 6. For each iteration, the DSE, KE, CE, the new Young's modulus $\left(E / E_{0}\right)$, and SET are presented. The observed features are (1) stiffening occurs along an arch, and (2) mass is preserved in the middle where oscillation is maximum, as in the case of modal dynamic redesign of the cantilever beam in Fig. 5.

Simultaneous static and modal dynamic redesign In this application, the bridge in Fig. 11 is redesigned simultaneously for the static and dynamic objectives shown in Table 1 . The results are shown in Fig. 14 and Table 7. For each iteration, the SSE, DSE, KE, CE, the new Young's modulus $\left(E / E_{0}\right)$, and SET are presented. In four iterations, the topology evolution process generates SET (4), which is more difficult to verify intuitively. Nevertheless, we can observe stiffening patterns along arches similar to those appearing in both the static and modal dynamic redesigns. Also, mass preservation to reach the required natural frequency matches that of modal dynamic redesign. Finally, voids which appear in both the static topology redesign and modal dynamic redesign also appear in the simultaneous redesign.

\subsection{Topology redesign of a clamped plate}

The original structure is shown in Fig. 15 and is modeled using $700(70 \times 10)$ solid elements, where Young's modulus is assumed $E_{0}=2.07 \times 10^{5} \mathrm{MPa}$, Poisson's ratio $\nu=0.3$, and density $\rho=.833 \times 10^{-9} \mathrm{~N} \mathrm{~s}^{2} / \mathrm{mm}^{4}$. One concentrated force, $F=5,000 \mathrm{~N}$, is applied at the center of the plate.

Static redesign As shown in Table 1, the static redesign objective is reduction of static displacement at the loading point by a factor of 2 . The results of topology and static performance redesign are shown in Fig. 16 and Table 8. For each

Table 4 Results of the cantilever plate for static and dynamic topology redesign

\begin{tabular}{|c|c|c|c|c|c|c|}
\hline $\begin{array}{r}\text { Iteration } \\
\text { number }\end{array}$ & $\begin{array}{l}\text { Static } \\
\left(u^{\prime} / u\right)\end{array}$ & $\begin{array}{l}\text { Redesign } \\
\quad(\text { error } \%)\end{array}$ & $\begin{array}{l}\text { Dynamic } \\
\left(\omega^{2 \prime} / \omega^{2}\right)\end{array}$ & $\begin{array}{l}\text { Redesign } \\
\quad(\text { error } \%)\end{array}$ & $\begin{array}{l}\text { Number of } \\
\text { redesign (variables) }\end{array}$ & $\mathrm{CE}$ (eliminate \%) \\
\hline 1 & 0.688 & 0.49 & 1.440 & 2.17 & 320 & 2.50 \\
\hline 2 & 0.724 & 3.22 & 1.410 & 1.23 & 279 & 3.50 \\
\hline 3 & 0.810 & 3.14 & 1.419 & 0.97 & 254 & 3.50 \\
\hline 4 & 0.755 & 3.63 & 1.429 & 0.48 & 248 & 4.50 \\
\hline 5 & 0.788 & 4.53 & 1.479 & 2.13 & 233 & 4.50 \\
\hline
\end{tabular}




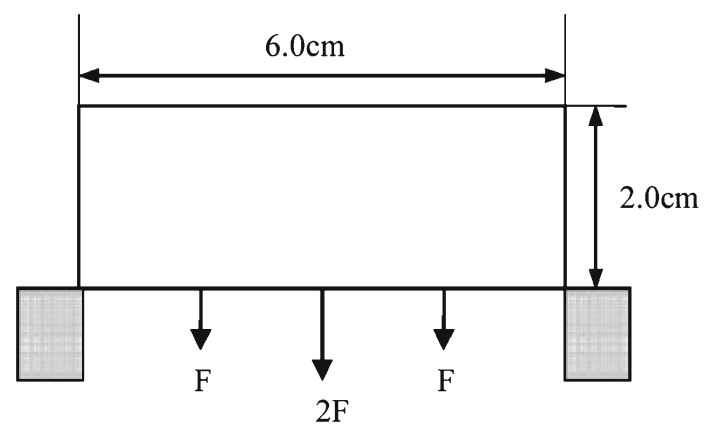

Fig. 11 Initial structure S1: bridge

iteration, the SSE, the new Young's modulus $\left(E / E_{0}\right)$, and SET are presented. In five iterations, the topology evolution process leads to the plate shown in SET (5), which has the following features: (1) patterns of repetitive sets of voids, (2) stiffened elements at the upper and lower surfaces, and (3) curved and straight elements.

Modal dynamic redesign As shown in Table 1, the modal dynamic objective is to increase the first eigenvalue (inplane
Table 5 Results of the bridge for static topology redesign

\begin{tabular}{lclll}
\hline $\begin{array}{c}\text { Iteration } \\
\text { number }\end{array}$ & $\begin{array}{c}\text { Static } \\
\left(u^{\prime} / u\right)\end{array}$ & $\begin{array}{c}\text { Redesign } \\
(\text { error \%) }\end{array}$ & $\begin{array}{c}\text { Number of } \\
\text { redesign } \\
\text { variables }\end{array}$ & $\begin{array}{c}\text { SSE } \\
(\text { eliminate \%) }\end{array}$ \\
\hline 1 & 0.589 & 3.47 & 216 & 0.70 \\
2 & 0.616 & 3.04 & 194 & 0.70 \\
3 & 0.608 & 2.16 & 171 & 0.70 \\
4 & 0.584 & 3.46 & 152 & 0.70 \\
5 & 0.628 & 4.20 & 111 & 0.70 \\
\hline
\end{tabular}

bending) by a factor of 1.44 . The results of topology and modal dynamic performance redesign are shown in Fig. 17 and Table 9. For each iteration, the DSE, KE, CE, the new Young's modulus $\left(E / E_{0}\right)$, and SET are presented. In three iterations, the topology evolution leads to the plate shown in SET (3). The part of the structure closer to the two clamped ends is stiffened similarly to the static redesign. The preserved mass in the center of the structure provides the mass needed to achieve the new natural frequency.

Simultaneous static and modal dynamic redesign In this application, the plate is redesigned simultaneously for the static and dynamic objectives shown in Table 1. The results are
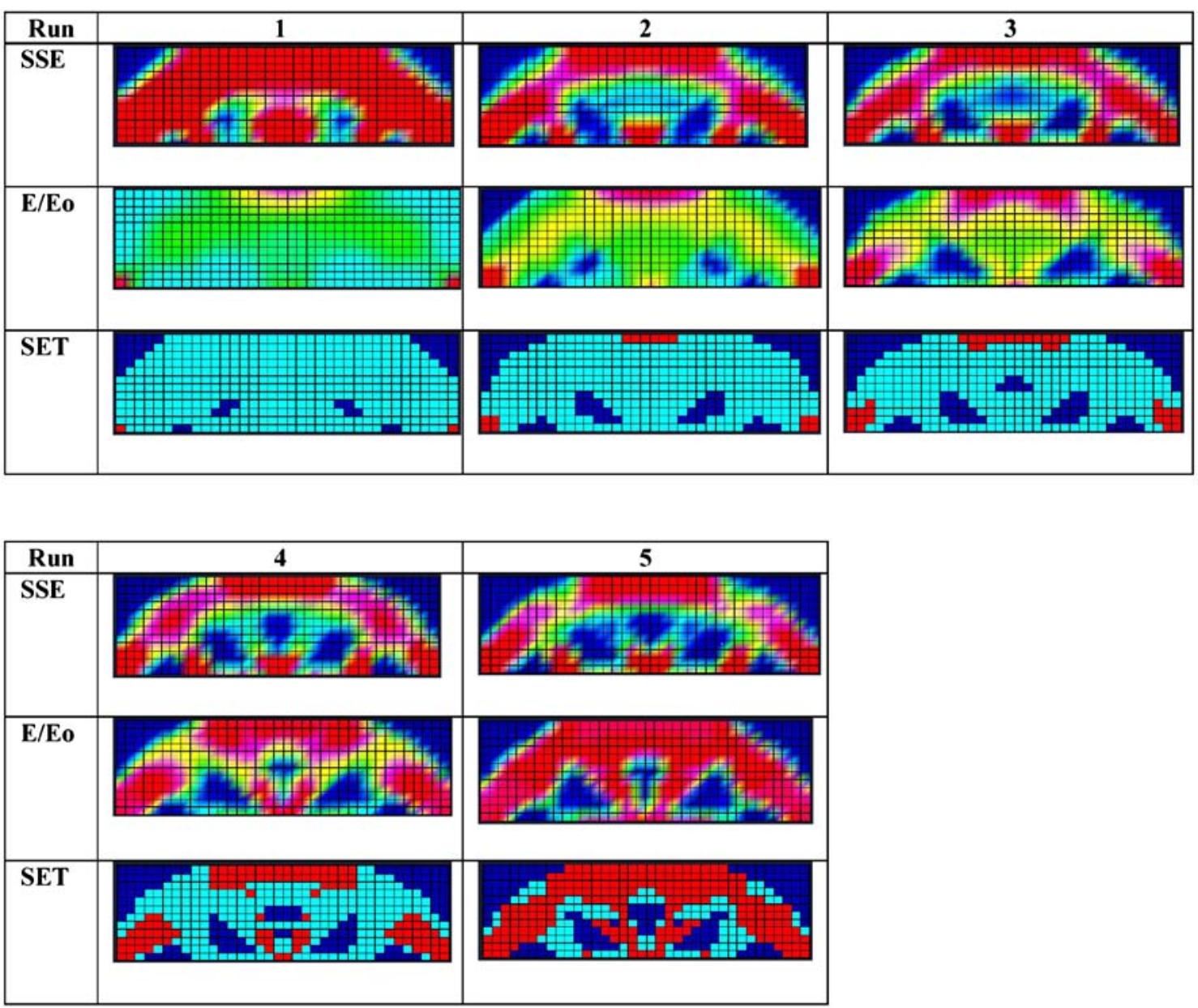

Fig. 12 Evolution of static topology redesign for bridge 


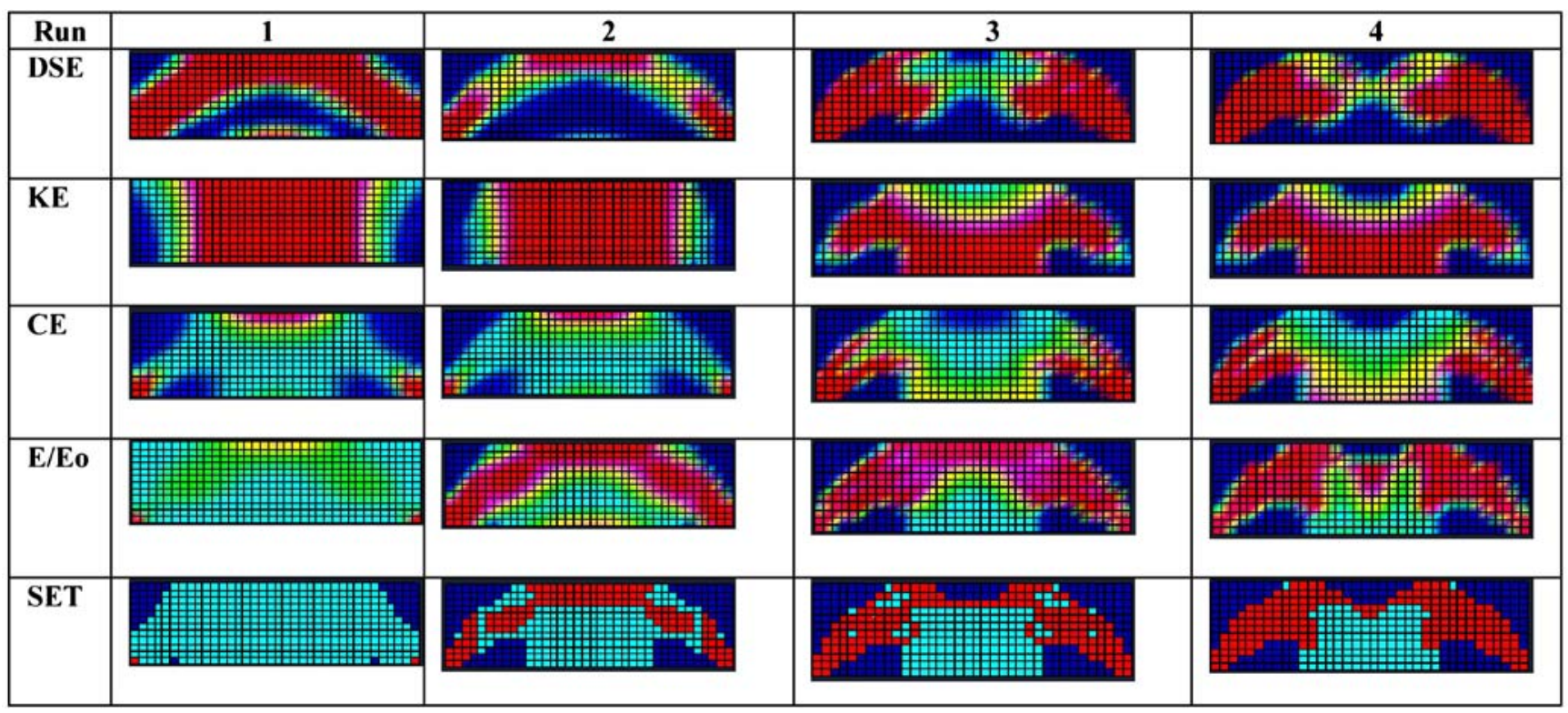

Fig. 13 Evolution of modal dynamic topology redesign for bridge

shown in Fig. 18 and Table 10. For each iteration, the SSE, DSE, KE, CE, the new Young's modulus $\left(E / E_{0}\right)$, and SET are presented. The evolution process leads to SET (4) in four iterations. It can be observed that the features of the new structure are a combination of the features of the static and modal dynamic redesigns.

\section{Closing remarks}

A topology design methodology for performance is developed. The performance constraints are treated by large admissible perturbations so that finite element calculations are reduced dramatically. Material properties are limited to voids, original Young modulus $E_{0}$, or $2.5 E_{0}$. Thus, the results in topology may not be so difficult to manufacture. The desired topology/material is achieved in four to five iterations for changes and performance by a factor of 2 . Benchmark applications show that the evolved topologies strongly depend on the performance constraints. Further, for simple examples, it is possible to verify the features of the evolved topologies on the basis of the performance constraints. However, in cases of multiple performance specifications, intuitive justification of the features of the evolved structure may be more difficult.

Table 6 Results of the bridge for dynamic topology redesign

\begin{tabular}{lcccc}
\hline $\begin{array}{c}\text { Iteration } \\
\text { number }\end{array}$ & $\begin{array}{c}\text { Dynamic } \\
\left(\omega^{2 /} / \omega^{2}\right)\end{array}$ & $\begin{array}{c}\text { Redesign } \\
(\text { error \%) }\end{array}$ & $\begin{array}{c}\text { Number of } \\
\text { redesign } \\
\text { variables }\end{array}$ & $\begin{array}{c}\text { CE } \\
(\text { eliminate \%) }\end{array}$ \\
\hline 1 & 1.690 & 0.75 & 216 & 2.00 \\
2 & 1.689 & 4.30 & 192 & 2.50 \\
3 & 1.688 & 5.06 & 97 & 4.00 \\
4 & 1.140 & 1.02 & 76 & 4.00 \\
\hline
\end{tabular}

Appendix A: General perturbation equation for static deflection with static mode compensation

In this appendix, the general perturbation equation for static deflection with static mode compensation is derived (Suryatama and Bernitsas 2000).

(16) can be written as

$\left[k^{\prime}\right]\left\{u^{\prime}\right\}=\{f\}$

assuming that $\left\{f^{\prime}\right\}=\{f\}$. If this is not the case, as in hydrodynamic loading of offshore platforms, see Bernitsas and Tawekal (1991). Let $\left\{Q^{\prime}\right\}$ be the transformed displacement vector, which is defined as

$\left\{u^{\prime}\right\}=\{u\}+\left[\Phi^{\prime}\right]\left\{Q^{\prime}\right\}$,

where $\left[\Phi^{\prime}\right]$ is the matrix of the unknown mode shape vectors of the objective structure

$\left[\Phi^{\prime}\right]=\left[\left\{\phi^{\prime}\right\}_{1}, \ldots,\left\{\phi^{\prime}\right\}_{n_{r}}\right]$.

Substituting (39) into (38) gives

$\left[k^{\prime}\right]\{u\}+\left[k^{\prime}\right]\left[\Phi^{\prime}\right]\left\{Q^{\prime}\right\}=\{f\}$.

Premultiplying (41) by $\left[\Phi^{\prime}\right]^{T}$ yields

$\left[\Phi^{\prime}\right]^{T}\left[k^{\prime}\right]\{u\}+\left[\Phi^{\prime}\right]^{T}\left[k^{\prime}\right]\left[\Phi^{\prime}\right]\left\{Q^{\prime}\right\}=\left[\Phi^{\prime}\right]^{T}\{f\}$.

Introducing the generalized stiffness diagonal matrix

$\left[K^{\prime}\right]=\left[\Phi^{\prime}\right]^{T}\left[k^{\prime}\right]\left[\Phi^{\prime}\right]$,

(42) becomes

$\left[K^{\prime}\right]\left\{Q^{\prime}\right\}=\left[\Phi^{\prime}\right]^{T}\{f\}-\left[\Phi^{\prime}\right]^{T}\left[k^{\prime}\right]\{u\}$.

Combining (14), (18), and (44) gives

$\left[K^{\prime}\right]\left\{Q^{\prime}\right\}=-\left[\Phi^{\prime}\right]^{T}[\Delta k]\{u\}$ 


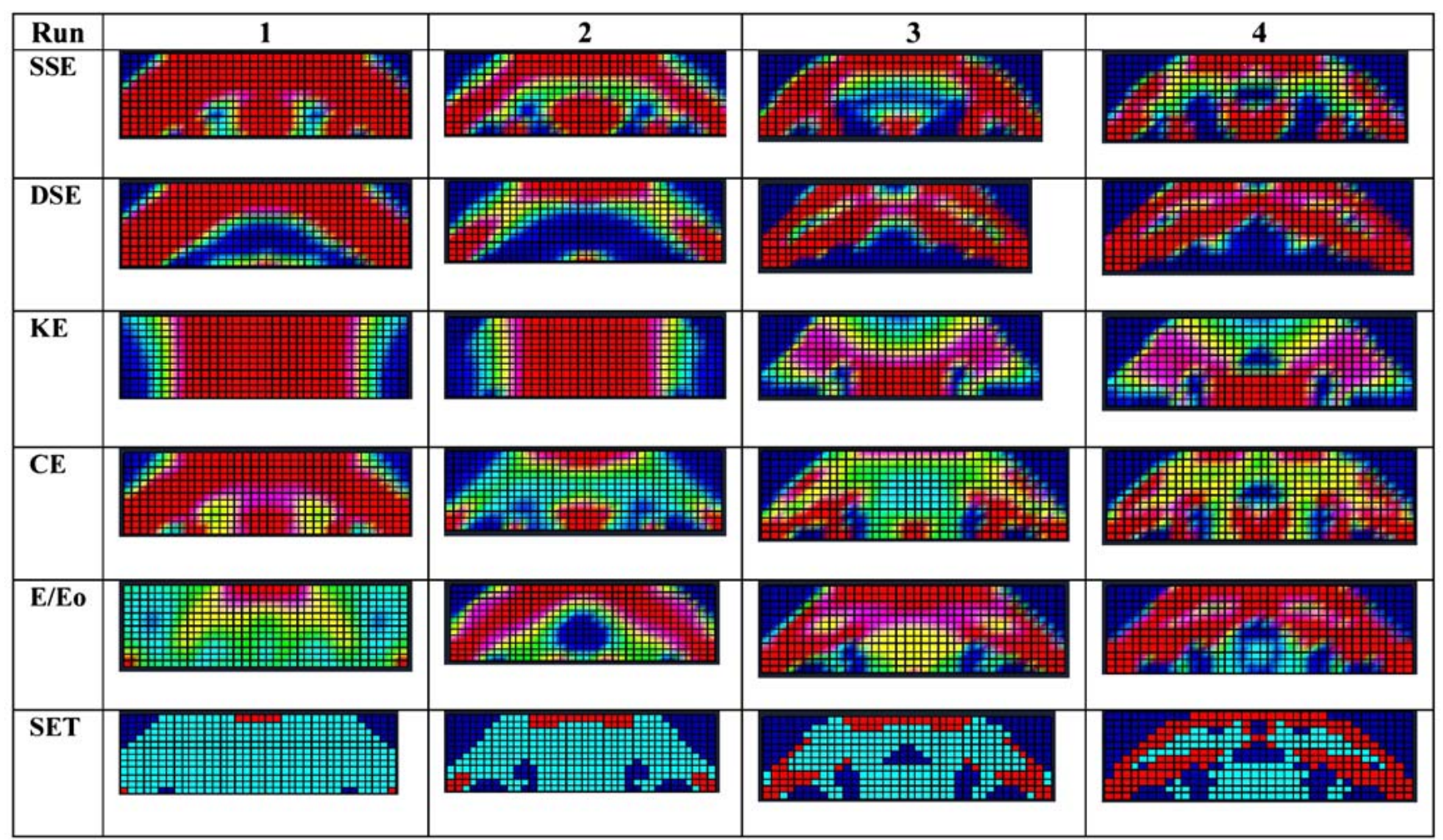

Fig. 14 Evolution of simultaneous static and modal dynamic topology redesign for bridge

Table 7 Results of the bridge for static and dynamic topology redesign

\begin{tabular}{lcccccr}
\hline $\begin{array}{c}\text { Iteration } \\
\text { number }\end{array}$ & $\begin{array}{c}\text { Static } \\
\left(u^{\prime} / u\right)\end{array}$ & $\begin{array}{c}\text { Redesign } \\
(\text { error } \%)\end{array}$ & $\begin{array}{c}\text { Dynamic } \\
\left(\omega^{2} / \omega^{2}\right)\end{array}$ & $\begin{array}{c}\text { Redesign } \\
(\text { error \%) }\end{array}$ & $\begin{array}{c}\text { Number of } \\
\text { redesign (variables) }\end{array}$ & $\begin{array}{c}\text { CE } \\
(\text { eliminate } \%)\end{array}$ \\
\hline 1 & 0.589 & 3.77 & 1.690 & 0.92 & 216 & 1.50 \\
2 & 0.601 & 4.40 & 1.689 & 4.19 & 195 & 2.00 \\
3 & 0.618 & 3.40 & 1.688 & 6.20 & 147 & 3.00 \\
4 & 0.674 & 5.00 & 1.481 & 6.90 & 120 & 3.00 \\
\hline
\end{tabular}

or

$\left\{Q^{\prime}\right\}=-\left[1 / K^{\prime}\right]\left[\Phi^{\prime}\right]^{T}[\Delta k]\{u\}$.

Substituting (46) into (39) produces

$\left\{u^{\prime}\right\}=\{u\}-\left[\Phi^{\prime}\right]\left[1 / K^{\prime}\right]\left[\Phi^{\prime}\right]^{T}[\Delta k]\{u\}$.

Finally, by combining (18), (25), and (43), the components of vector $\left\{u^{\prime}\right\}$ are obtained as

$u_{i}^{\prime}=u_{i}-\sum_{m=1}^{n_{r}} \phi_{i, m}^{\prime} \frac{\sum_{e=1}^{p}\left\{\phi^{\prime}\right\}_{m}^{T}\left[k_{e}\right]\{u\} \alpha_{e}}{\left\{\phi^{\prime}\right\}_{m}^{T}\left[k_{e}\right]\left\{\phi^{\prime}\right\}_{m}+\sum_{e=1}^{p}\left\{\phi^{\prime}\right\}_{m}^{T}\left[k_{e}\right]\left\{\phi^{\prime}\right\}_{m} \alpha_{e}}$,

where $\phi_{i, m}^{\prime}$ represents the amplitude of the $i$-th $d o f$ of mode $m$.

\section{Appendix B: General perturbation equation for modal dynamics}

In this appendix, the general perturbation equation for modal dynamics is derived (see Hoff and Bernitsas 1985).
(15) for the objective structure S2 can also be written as

$\left[K^{\prime}\right]=\left[M^{\prime}\right]\left[\omega^{\prime 2}\right]$,

where primed quantities refer to state S2. The counterpart of (43) for $\left[K^{\prime}\right]$ is $(50)$ for $\left[M^{\prime}\right]$, which is the generalized mass matrix of the objective structure

$\left[M^{\prime}\right]=\left[\Phi^{\prime}\right]^{T}\left[m^{\prime}\right]\left[\Phi^{\prime}\right]$.

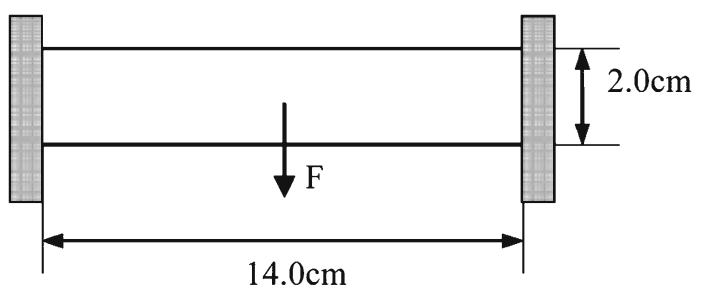

Fig. 15 Initial structure S1: clamped plate 

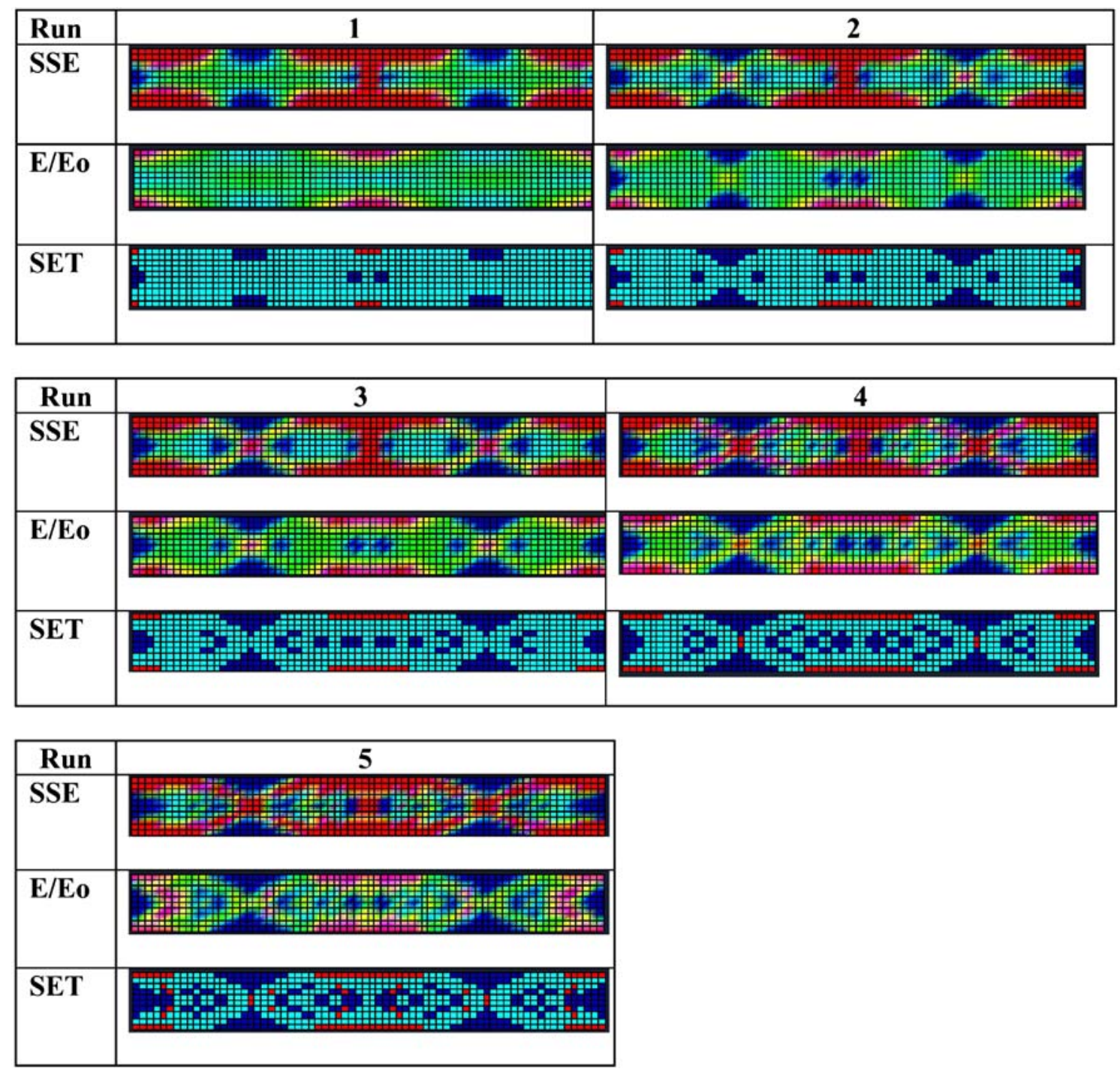

Fig. 16 Evolution of static topology redesign for clamped plate

Substituting relationships in (18)-(20) and (25)-(26) into (49), the dynamic general perturbation equation is derived as

$$
\begin{array}{r}
{\left[\Phi^{\prime}\right]^{T}[\Delta k]\left[\Phi^{\prime}\right]-\left[\Phi^{\prime}\right]^{T}[\Delta m]\left[\Phi^{\prime}\right]\left[\omega^{\prime 2}\right]=\left[\Phi^{\prime}\right]^{T}[m]\left[\Phi^{\prime}\right]\left[\omega^{\prime 2}\right]} \\
-\left[\Phi^{\prime}\right]^{T}[k]\left[\Phi^{\prime}\right] .
\end{array}
$$

Table 8 Results of clamped beam for static topology redesign

\begin{tabular}{lllll}
\hline $\begin{array}{c}\text { Iteration } \\
\text { number }\end{array}$ & $\begin{array}{c}\text { Static } \\
\left(u^{\prime} / u\right)\end{array}$ & $\begin{array}{c}\text { Redesign } \\
(\text { error \%) }\end{array}$ & $\begin{array}{c}\text { Number of } \\
\text { redesign } \\
\text { (variables })\end{array}$ & $\begin{array}{c}\text { SSE } \\
(\text { eliminate \%) }\end{array}$ \\
\hline 1 & 0.600 & 0.97 & 175 & 4.00 \\
2 & 0.625 & 4.53 & 157 & 4.50 \\
3 & 0.605 & 6.01 & 142 & 5.50 \\
4 & 0.601 & 6.66 & 127 & 6.00 \\
5 & 0.595 & 7.01 & 112 & 6.00 \\
\hline
\end{tabular}

(51) consists of $n^{2}$ scalar equations of the following form:

$$
\begin{aligned}
\sum_{e=1}^{p}\left(\left\{\phi^{\prime}\right\}_{j}^{T}\left[k_{e}\right]\left\{\phi^{\prime}\right\}_{i}-\omega{ }_{i}^{2}\left\{\phi^{\prime}\right\}_{j}^{T}\left[m_{e}\right]\left\{\phi^{\prime}\right\}_{i}\right) \alpha_{e} & =\omega_{\prime}^{\prime 2}\left\{\phi^{\prime}\right\}_{j}^{T}[m]\left\{\phi^{\prime}\right\}_{i} \\
& -\left\{\phi^{\prime}\right\}_{j}^{T}\left[k_{e}\right]\left\{\phi^{\prime}\right\}_{i}
\end{aligned}
$$

for $i, j=1,2, \ldots, n$. For $i=j$, these are the general perturbation equations. For $i \neq j$, these are the linearized admissible conditions.

\section{Appendix C: Linear prediction for eigenvectors}

The eigenvectors used in (48) are unknown. In matrix form, the $i$-th mode free vibration equation for the initial and desired structures can be written as

$[k]\{\phi\}_{i}=[m]\{\phi\}_{i} \omega_{i}^{2}$,

$\left[k^{\prime}\right]\left\{\phi^{\prime}\right\}_{i}=\left[m^{\prime}\right]\left\{\phi^{\prime}\right\}_{i} \omega_{i}^{\prime 2}$, 


\begin{tabular}{|c|c|c|}
\hline Run & 1 & 2 \\
\hline DSE & 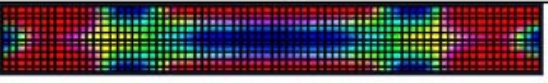 & 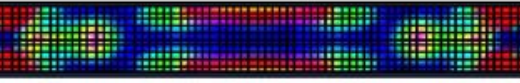 \\
\hline KE & 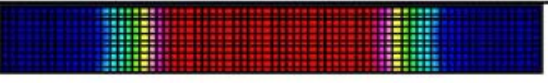 & 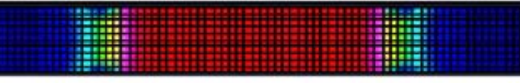 \\
\hline CE & 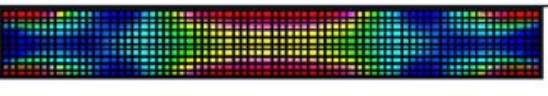 & 玤 \\
\hline E/Eo & 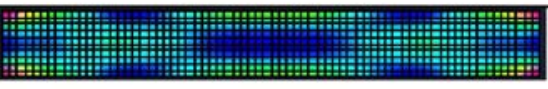 & 曹, \\
\hline SET & 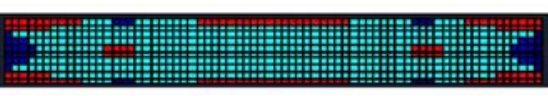 & 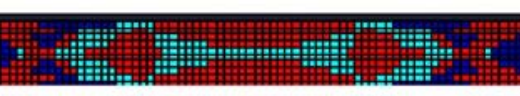 \\
\hline
\end{tabular}

\begin{tabular}{|c|c|}
\hline Run & 3 \\
\hline DSE & 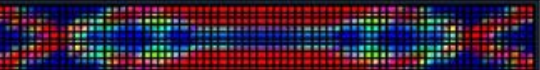 \\
\hline $\mathbf{K E}$ & 坓 \\
\hline CE & (N) \\
\hline E/Eo & 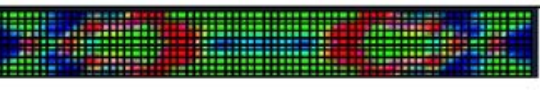 \\
\hline SET & \\
\hline
\end{tabular}

Fig. 17 Evolution of modal dynamic topology redesign for clamped plate

where $\omega_{i}^{2}$ is the $i$-th eigenvalue corresponding to the $i$-th eigenvector $\{\phi\}_{i}$. The perturbation relations are

$\left\{\phi^{\prime}\right\}_{i}=\{\phi\}_{i}+\{\Delta \phi\}_{i}$,

$\omega_{i}^{\prime 2}=\omega_{i}^{2}+\Delta \omega_{i}^{2}$.

Premultiplying (54) by $\left\{\phi^{\prime}\right\}_{i}^{T}$ and using (18)-(19) and (55)-(56) yields an equation that can be developed into 24 terms, 15 of which are nonlinear terms in $[\Delta(\ldots)]^{2}$ and $[\Delta(\ldots)]^{3}$. Assume small perturbations to linearize this equation by keeping the nine linear terms as follows:

$$
\begin{aligned}
& \{\phi\}_{j}^{T} k\{\phi\}_{i}+\{\phi\}_{j}^{T}[\Delta k]\{\phi\}_{i}+\{\phi\}_{j}^{T}[k]\{\Delta \phi\}_{i}+\{\Delta \phi\}_{j}^{T}[k]\{\phi\}_{i}= \\
& \{\phi\}_{j}^{T}[m]\{\phi\}_{i} \omega_{i}^{2}+\{\phi\}_{j}^{T}[m]\{\phi\}_{i} \Delta \omega_{i}^{2}+\{\phi\}_{j}^{T}[\Delta m]\{\phi\}_{i} \omega_{i}^{2} \\
& +\{\phi\}_{j}^{T}[m]\{\Delta \phi\}_{i} \omega_{i}^{2}+\{\Delta \phi\}_{j}^{T}[m]\{\phi\}_{i} \omega_{i}^{2} .
\end{aligned}
$$

Table 9 Results of clamped beam for dynamic topology redesign

\begin{tabular}{lllll}
\hline $\begin{array}{c}\text { Iteration } \\
\text { number }\end{array}$ & $\begin{array}{c}\text { Dynamic } \\
\left(\omega^{2 /} / \omega^{2}\right)\end{array}$ & $\begin{array}{c}\text { Redesign } \\
(\text { error \%) }\end{array}$ & $\begin{array}{c}\text { Number of } \\
\text { redesign } \\
\text { (variables })\end{array}$ & $\begin{array}{c}\mathrm{CE} \\
(\text { eliminate \%) }\end{array}$ \\
\hline 1 & 1.687 & 4.21 & 175 & 5.50 \\
2 & 1.535 & 5.32 & 134 & 7.00 \\
3 & 1.386 & 5.41 & 50 & 9.00 \\
\hline
\end{tabular}

For $i=j$, using (53) and its transpose yields

$\{\phi\}_{i}^{T}[\Delta k]\{\phi\}_{i}-\{\phi\}_{i}^{T}[\Delta m]\{\phi\}_{i} \omega_{i}^{2}=M_{i} \Delta \omega_{i}^{2}$,

where $M_{i}$ is the $i$-th diagonal term of the generalized mass matrix. For $i \neq j,\{\phi\}_{j}^{T}[m]\{\phi\}_{i}=0$, and using the transpose of (53) for the $j$-th mode (57) yields

$\{\phi\}_{j}^{T}[\Delta k]\{\phi\}_{i}-\{\phi\}_{j}^{T}[\Delta m]\{\phi\}_{i} \omega_{i}^{2}=\{\phi\}_{j}^{T}[m]\{\Delta \phi\}_{i}\left(\omega_{i}^{2}-\omega_{j}^{2}\right)$.

Assume that the changes in eigenvectors can be written as

$[\Delta \Phi]=[\Phi][C]^{T}$,

where $[C]$ is the matrix of admixture coefficients with $C_{i i}=0$ and $C_{i j}$ small for $i \neq j$. In scalar form, (60) can be written as

$\Delta \phi_{i, m}=\sum_{k=1}^{n_{r}} \phi_{i, k} C_{m k}$,

where $i$ indicates the degree of freedom, and $m$ indicates the mode vector. Then, $C_{m k}$ is the contribution factor of mode $k$ to a change in mode $m$. Physical interpretation of (61) can be as follows. For a 3-D structure, three major types of mode shapes exist: stretching modes, bending modes, and torsional modes. It can be expected that a mode of one type has little effect on the change in a mode of the other two types, which results into small values for the corresponding admixture coefficients. For repeated eigenvalues, the admixture coefficients between modes or repeated eigenvalues are zero. That is, the singularity is removable. 

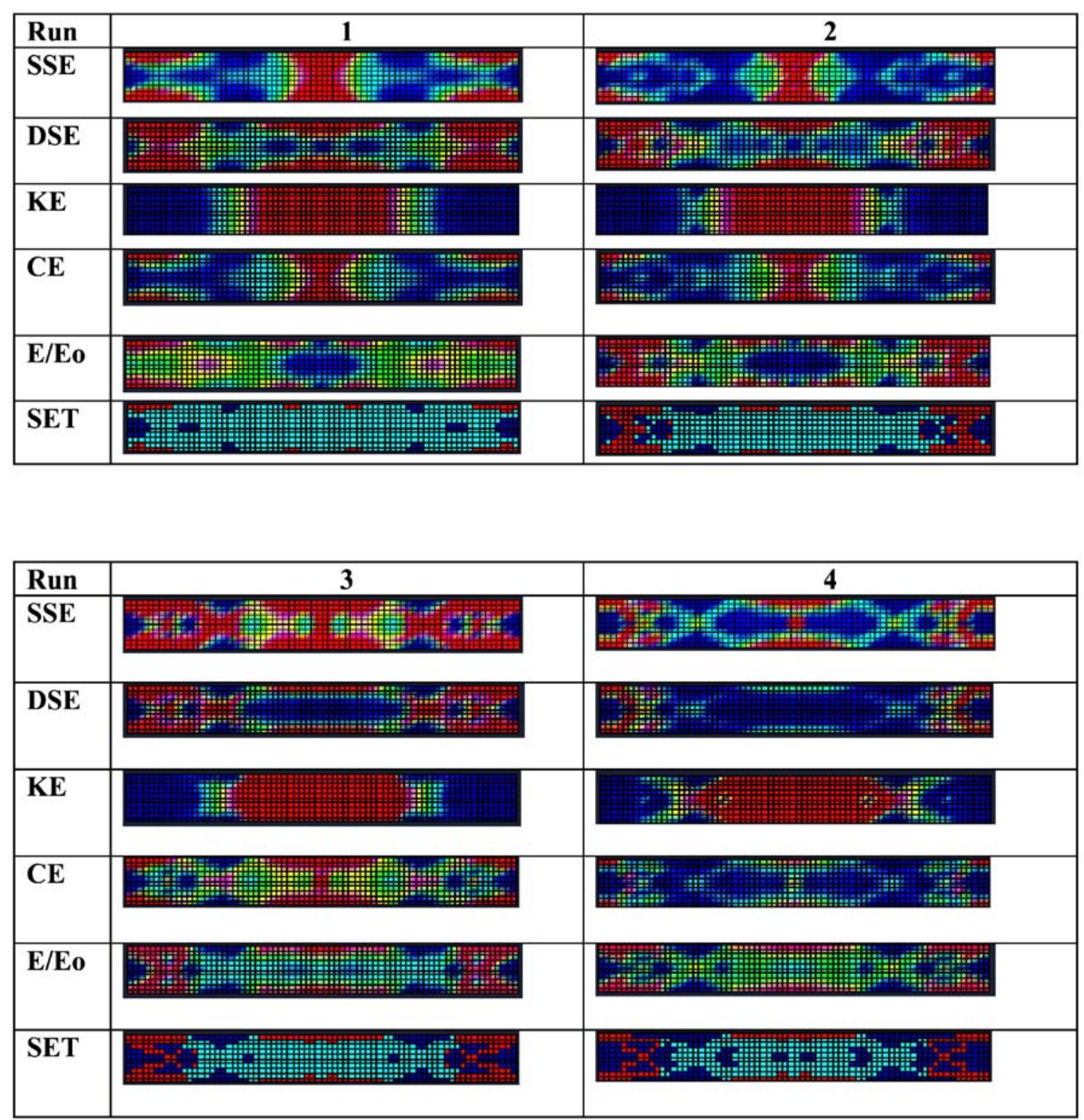

Fig. 18 Evolution of simultaneous static and modal dynamic topology redesign for clamped plate

Substituting (60) into (59) yields

$C_{i j}=\frac{1}{M_{j}\left(\omega_{i}^{2}-\omega_{j}^{2}\right)}\left(\{\phi\}_{j}^{T}[\Delta k]\{\phi\}_{i}-\{\phi\}_{j}^{T}[\Delta m]\{\phi\}_{i} \omega_{i}^{2}\right)$, initial structure and those of the new structure where small changes were assumed.

where $M_{j}$ is the $j$-th diagonal term of the generalized mass matrix. Equations 50 55, 61 and provide the relation between the modes of the

\section{Nomenclature}

$\left[B_{e}\right] \quad$ Element strain-nodal displacement matrix

$[C] \quad$ Matrix of admixture coefficients

Table 10 Results of clamped beam for static and dynamic topology redesign

\begin{tabular}{llllcrr}
\hline $\begin{array}{c}\text { Iteration } \\
\text { number }\end{array}$ & $\begin{array}{c}\text { Static } \\
\left(u^{\prime} / u\right)\end{array}$ & $\begin{array}{c}\text { Redesign } \\
(\text { error } \%)\end{array}$ & $\begin{array}{c}\text { Dynamic } \\
\left(\omega^{2 /} / \omega^{2}\right)\end{array}$ & $\begin{array}{c}\text { Redesign } \\
(\text { error \%) }\end{array}$ & $\begin{array}{c}\text { Number of } \\
\text { redesign (variables) }\end{array}$ & $\begin{array}{c}\text { CE } \\
(\text { eliminate \%) }\end{array}$ \\
\hline 1 & 0.600 & 6.17 & 1.687 & 4.14 & 175 & 4.00 \\
2 & 0.621 & 5.05 & 1.682 & 5.00 & 146 & 5.00 \\
3 & 0.620 & 5.98 & 1.687 & 5.27 & 105 & 7.00 \\
4 & 0.830 & 5.22 & 1.213 & 4.26 & 85 & 9.00 \\
\hline
\end{tabular}




$\begin{array}{ll}{\left[D_{e}\right]} & \text { Element constitutive law matrix } \\ \mathrm{dof}(\mathrm{s}) & \text { Degree(s) of freedom } \\ E & \text { Young's modulus } \\ E_{e} & \text { Element Young's modulus } \\ E_{0} & \text { Initial Young's modulus } \\ {[k],[K]} & \text { Global and generalized stiffness matrix, respectively } \\ {\left[k_{e}\right]} & \begin{array}{l}\text { Stiffness matrix of element or group of elements } \\ \text { related to property e }\end{array} \\ l & \text { Increment number } \\ \text { LEAP } & \text { LargE Admissible Perturbation } \\ {[m],[M]} & \text { Global and generalized mass matrix, respectively } \\ {\left[m_{e}\right]} & \text { Mass matrix of element or group of elements related } \\ & \text { to property e } \\ n & \text { Number of degrees of freedom of structural model } \\ n_{\mathrm{a}} & \text { Number of admissibility equations used in redesign } \\ n_{e} & \text { Number of elements of structural model } \\ {\left[N_{e}\right]} & \text { Interpolation function matrix for each element } \\ n_{\mathrm{r}} & \text { Number of the extracted modal dynamic modes } \\ n_{u} & \text { Number of displacement constraints } \\ n_{\omega} & \text { Number of natural frequency constraints } \\ n_{d} & \text { Number of forced response amplitude constraints } \\ n_{\sigma} & \text { Number of static stress constraints } \\ p & \text { Number of redesign variables } \\ \text { RESTRUCT } & \text { Program for REdesign of STRUCTures } \\ \mathrm{S} 1 & \text { The baseline state of the structure to be redesigned } \\ \mathrm{S} 2 & \text { The unknown objective structural state satisfies de- } \\ & \text { signer specifications after completing this state } \\ \{\mathrm{u}\} & \text { Nodal static displacement vector } \\ V_{e} & \text { Element volume } \\ & \end{array}$

\section{Greek symbols}

$\alpha_{\mathrm{e}} \quad$ Fractional change of an element or group of elements

$\Delta \quad$ Change between the initial State S1 and the unknown State S2

[Ф] Dynamic mode shape matrix

$\{\phi\}_{i} \quad i$-th dynamic mode shape vector

$\omega_{i}^{2} \quad i$-th modal dynamic eigenvalue

\section{Other symbols}

()$^{\prime} \quad$ Prime indicates objective structure

\section{References}

Bendsoe MP, Kikuchi N (1988) Generating optimal topology in structural design using a homogenization method. Comput Methods Appl Mech Eng 71:197-224

Bernitsas MM, Blouin V (1999) Structural redesign for forced response amplitude with proportional damping by large admissible perturbations. AIAA J 37(11):1506-1513

Bernitsas MM, Rim CW (1994) Redesign of plates by large admissible perturbations. AIAA J 32(5):1021-1028

Bernitsas MM, Suryatama D (1999) Structural redesign by large admissible perturbations with static mode compensation. J Offshore Mech Arct Eng 121(1):39-46

Bernitsas MM, Tawekal RL (1991) Structural model correlation using large admissible perturbation in cognate space. AIAA J 29(12):2222-2232

Cheng KT, Olhoff N (1981) An investigation concerning optimal design of solid elastic plates. Int J Solids Struct 17:305-323

Hoff CJ, Bernitsas MM (1985) Dynamic redesign of marine structures. J Ship Res 29(4):285-295

Kim JH, Bernitsas MM (1990) Redesign of marine structures. Mar Struct 1(2):139-183

Kohn RV, Strang G (1986) Optimal design and relaxation of variational problems. Comm Pure Appl Math 39(Part I):113-137; (Part II):139-182; (Part III):353-377

Bernitsas MM, Kristanto BK (2003) Static stress redesign of structures by large admissible perturbations. J Offshore Mech Arct Eng 127:122-129 (also proceedings of the 22nd international conference on offshore mechanics and arctic engineering (OMAE '03), paper no. 37207, Cancun, 8-13 June 2003)

Ma ZD, Kikuchi N, Cheng HC (1995) Topological design for vibrating structures. Comput Methods Appl Mech Eng 121:259-280

Mattheck C, Tesari I (2002) Integrating biological optimization methods into engineering design process. Design and nature 2002 first international conference, Udine, 10-12 Sept 2002

Pasini D, Burgess SC (2002) Optimal structural features in trees and their application in engineering. Design and nature 2002 first international conference, Udine, 10-12 Sept 2002

Suryatama D, Bernitsas MM (2000) Topology and performance redesign of complex structures by large admissible perturbations. Struct Multidiscipl Optim 20:138-153

Walters GA (2002) Designing tree-like engineering networks by mimicking evolution. Design and nature 2002 first international conference, Udine, 10-12 Sept 2002

Xie YM, Steven GP (1993) A simple evolutionary procedure for structural optimization. Comput Struct 49:885-896

Yang RJ, Chuang CH (1994) Optimal topology design using linear programming. Comput Struct 52-2:265-275 